\title{
Waterfront Public Realm Design: Towards a Sustainable Identity Urban Projects in Vancouver and Portland
}

\author{
Elena Lacilla ${ }^{1,2} \&$ José María Ordeig ${ }^{1}$ \\ ${ }^{1}$ School of Architecture of the University of Navarra, Pamplona, Spain \\ ${ }^{2}$ School of Architecture and Allied Arts of the University of Oregon, Eugene, United States \\ Correspondence: Elena Lacilla, Urban Planning Area, School of Architecture of the University of Navarra, \\ Pamplona 31008, Spain. E-mail: mlacilla@unav.es
}

\author{
Received: January 3, 2016 Accepted: February 5, 2016 Online Published: March 30, 2016 \\ doi:10.5539/jsd.v9n2p169 URL: http://dx.doi.org/10.5539/jsd.v9n2p169
}

\begin{abstract}
The renovation of the waterfronts, such as those in the main public spaces of large cities, started in 1970s. Core industries had found other places to develop far from the city; thereafter key areas fell out of use and into disrepair. As a consequence, a huge number of urban areas became in urgent need of renewal. However, urban design guidelines to regenerate these open spaces have significantly changed since then. The approach towards returning these parts of the city to its inhabitants has evolved from an emphasis on building new housing in the nineties, to considering the broader aspects of sustainability in the early years of the current century and finally to searching for the areas' identity in more recent years. Therefore, currently this identity is one of the main aspects designers are looking for. At the same time, the sustainability of the waterfront areas may be achieved through the establishment of this place's sense of identity. In order to do this, we assess three urban actions undertaken in Portland and Vancouver -False Creek North, South Waterfront and Southeast False Creek-. The article suggests that the interplay between urban design, sustainability and identity is becoming the new driver for the design of the waterfronts.
\end{abstract}

Keywords: identity, Portland, sustainability, urban design, Vancouver, waterfront

\section{Introduction}

The whole process of waterfront design has evolved, changing the landscape over the last two decades; first of labor, then of leisure. We show this through a review of three waterfront urban action projects carried out in two cities of the Northwest American continent: Vancouver and Portland. In Vancouver, we selected False Creek North and Southeast False Creek (FCN and SEFC from now on) and in Portland, South Waterfront (SoWa from now on). These areas were chosen as best practice in sustainability: Portland being a leader in the field within the United States, and Vancouver for its worldwide reputation for good policies and practices.

This article has set itself the specific task of finding out how the meaning of sustainable identity may be interpreted in three case studies of waterfront urban action, focusing on five aspects of the urban design: urban fabric, main use, waterfront greenways, public parks and streets.

However, through these examples of urban action we will notice that over the years the guidelines regarding sustainability and identity have changed. The first urban action case study (FCN) does not follow either sustainability or identity guidelines. In the second one (SoWa), the sustainability guidelines are adhered to carefully and identity criteria start to appear. Finally, in the last urban project (SEFC) the sustainability identity is the main guideline followed for the urban design. Therefore, the operational guidelines for sustainable identity in urban design will be presented at the end.

We will look at why one does not have sustainable identity and the process whereby it can be obtained. However firstly let us consider the different case studies.

\section{Material Studied}

Before addressing each case study it is necessary to introduce what we mean by sustainability and identity. The most well-known definition of sustainable development: "meeting the needs of the present generation without compromising the ability of future generations to meet their own needs" (Note 1), is applicable to numerous 
fields such as economic throughput of materials (Daly, 1996), measures of ecological footprint (Rees \& Wackernagel, 1996), key stocks of critical natural capital (Pearce, 1993) and back-casting from system principles (James \& Lahti, 2004) among others. This paper focuses on sustainability as an empirical observation of real projects in open spaces where local natural resources were used to create a safe and livable environment for the future of these places.

Despite the notion of identity being a key concept, it is difficult to define as it cannot be summarized in a brief factual description. The identity of a person consists of a set of elements and patterns that determine the world they belongs to. To clarify this point Norberg-Schulz states that "when a person wants to tell who he is, it is in fact usual to say: 'I am a New Yorker', or 'I am a Roman'. This means something much more concrete than to say: 'I am an architect', or perhaps: 'I am an optimist'. We understand that human identity is to a high extent a function of places and things... It is therefore not only important that our environment has a spatial structure for our orientation, but that it also consists of concrete objects of identification. Human identity presupposes the identity of places." To this end, Relph (1976) identified three interrelated components that can be expressed in any identifiable place, creating its specific identity: "physical features or appearance, observable activities and functions, and meanings or symbols". These factors contribute to the creation of the unique personality of the urban forms and of the people who live there, which is very much linked to the past meanings of the place. This article aims at defining such identity using real examples that best represent the respect -by preservation, reconstruction and enhancement- for the sites' unique natural, social, and historical heritage. These examples also achieve the right equilibrium in the relationship to surrounding communities, enhancing the vitality, diversity, cultural richness and the sense of the places.

The concept of sustainability and identity are related to each other. Sustainability, besides securing a meaningful heritage for future generations, contributes many other advantages to the community such as livability, respect, awareness, vitality, diversity and identity among others. If sustainability could be understood as respect for the natural heritage that guarantees a healthy future, identity could be expressed as the respect for the human heritage that guarantees people's identity in the future. These concepts are interrelated because "if there is a strong social identity in a community, the horizon of sustainability is potentially more viable and vice versa" (Marichela Sepes, 2013).

\section{Area Descriptions}

The research strategy was begun by visiting the sites, taking some pictures, and making an analysis of the official documents that have guided the building process. After writing a draft of the paper, we returned to the areas and conducted some interviews and surveys on the people of the sites. We consider that the opinions and experiences of the sites' citizens to be of equal importance to the reading from the plan. It helped us to improve the approach of the paper related to the identity. This previous work was drafted during a visiting scholar's stay at the School of Architecture and Allied Arts of the University of Oregon.

Following this, we conducted an exhaustive analysis of the public realm resulting from a workshop carried out in the University of Oregon with a group of students during the summer of 2014. They proposed several solutions for improving different free spaces in these areas. It was especially useful for the study of their open space.

As a result of the collection of data and information, we carried out the redaction of the final paper. Firstly we took into account the urban fabric. Secondly, we studied the main uses to notice the relation between sustainability and identity with the mixed use. And finally we analyzed the design of the greenways, public parks and streets.

\section{Results}

\subsection{Towards a Sustainable Identity through Urban Fabric}

It is important to know the density of these areas. They present a density of approximately $30 \mathrm{sqm} / \mathrm{inhabitant}$, which was calculated by removing everything except the buildings and studying their volumes and uses. Let us consider each of them with regard to the urban fabric.

In FCN Vancouver the plot provides a continuous green line fifty feet wide. It is shaped by the large empty spaces between buildings. As a consequence, the public parks take orthogonal forms to adapt to the existing grid. The buildings' mass presents a great contrast to the public realm with thirty-two-storey towers on three-storey basements. The housing typology of these basements consists of single-family apartments, which create a façade onto the waterfront greenway, the public parks and the streets, providing additional private spaces. Taller buildings are located in the corners of every block. They offer views over False Creek, seeking a relationship with the surrounding, existing city and provoking memories of the old urban fabric. This contributes to the site's 
identity, as does the preservation of an old industrial building, the CPR Roundhouse, which provides a circular open space at the heart of the neighborhood.

In SoWa Portland the urban fabric creates a continuous greenway. A big public park in its center creates a subtle change to the urban grid. Initially the greenway is one hundred feet wide but soon it may potentially extend to 150 feet through a trade off planning mechanism, which allows higher building heights in return for recessing the building alignments. Further incentives were introduced to support the development of the district's open space network and other public objectives. The mass of SoWa Portland has a similar bulk to FCN Vancouver albeit the apartment units in the basements of the tall towers create a more varied façade, different building forms and urban spaces that better improve the connection to the waterfront greenway, the public parks and the streets. Taller buildings are designed to achieve a visual link with the riverbank Willamette River. The result is an improved sense of identity for the whole district.

In SEFC Vancouver the waterfront greenway follows the site's natural lines taking an organic form rather than a geometric one. This produces a permeable urban fabric, which includes many pedestrian paths running from First Avenue and potentially Second Avenue, to the waterfront park. The urban fabric consists of three neighboring precincts -the Worksyard, the Shipyard and the Railyard-. They are shaped by the historic pattern and use of the site, its adjacent communities and by False Creek itself. Here the public realm creates a distinct neighborhood identity. Five heritage buildings with historic value have been kept within the district. Unlike the previous two urban actions, here the mass is homogeneous. It creates a legible form that reinforces the idea of the False Creek 'basin', consisting of low buildings by the waterfront, which increase in height between First and Second Avenue where they draw upon the industrial legacy of the area manifesting a robust character. Low, mid-rise and terraced apartment buildings frame significant public parks and complete sightlines.

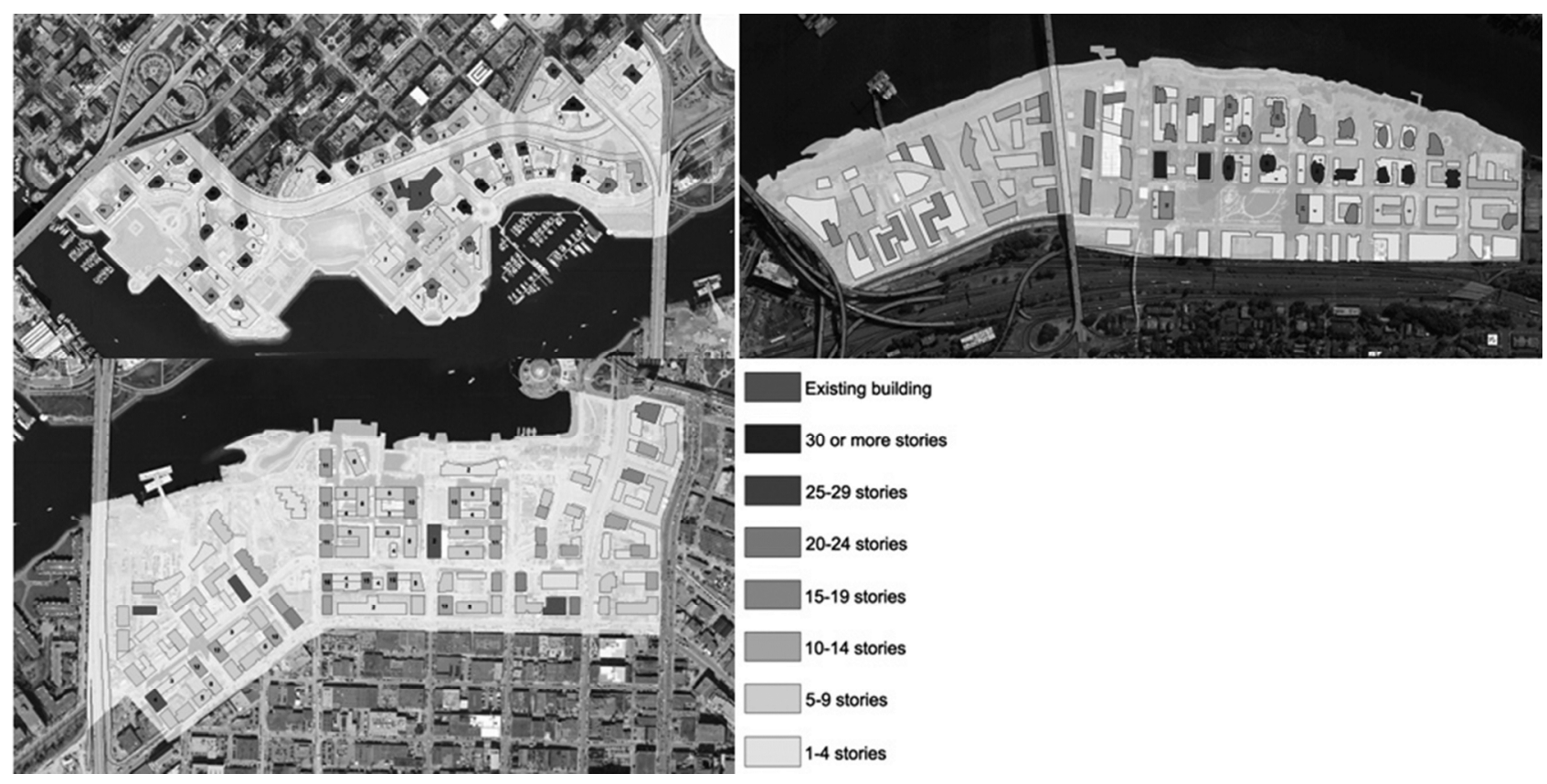

Figure 1. The mass of the three urban action projects

\subsection{Towards a Sustainable Identity through Main Uses}

Main use is different depending on the urban project. It varies from residential and retail use to service or offices. This means that the use depends on the urban design and vice versa. And it is related to sustainability and identity. Firstly, FCN Vancouver is fully residential in use except for one office/retail building in Pacific Boulevard, therefore it looks like there is no interest here in creating a public waterfront greenway.

On the contrary, SoWa Portland district presents a wide variety of housing, office, retail, recreational and institutional facilities of urban density. This presents a balance of work and housing (10.000 jobs and at least 3.000 housing units by 2019) which enhances the vitality, prosperity, livability and attractiveness of the area, reducing congestion. Office and research uses are prevalent on the northern portion of the district and along the western edge to combat noise from the I-5 freeway and Macadam Avenue forming a screen for the residential 
development. Retail uses are focused along Arthur, Gibbs and Lowell Street to provide key connections between the urban part of the district and the riverfront. The active use of the ground floor level, which includes lobbies, retail, residential and office is intended to reinforce the pedestrian continuity and the relationship between building and street.

In SEFC Vancouver mixed-use is achieved through the height of the buildings with retail on the ground floor, office on the first floor and residential use in the rest. Retail and services are located by the waterfront and in the streets perpendicular to it, in order to link, reinforce and extend existing street-related retail patterns and achieve an active waterfront. In addition to this, cultural, recreational, and institutional uses are located where they best suit the projected population and complement adjacent uses.

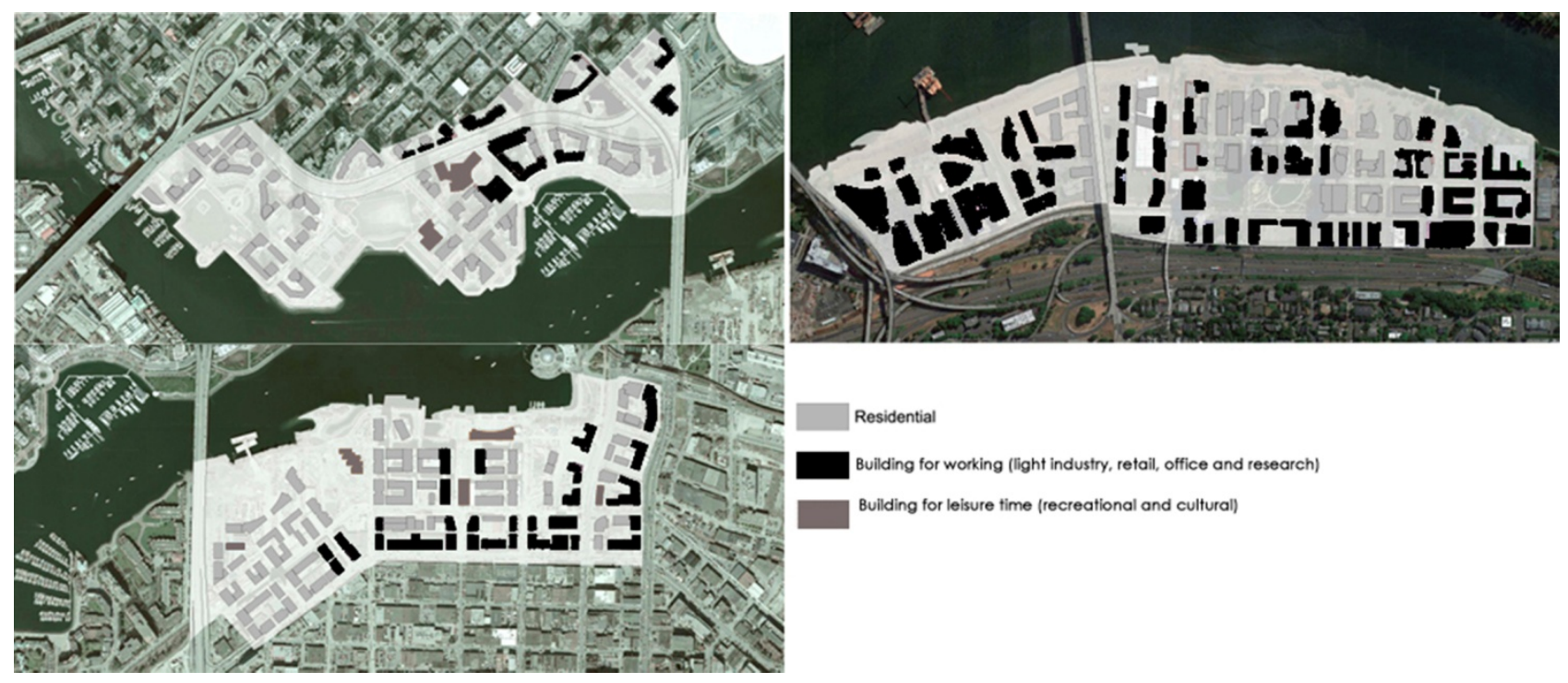

Figure 2. The mixed-use in the three urban action projects

\subsection{Towards a Sustainable Identity through Greenway Design}

The greenway is the most important open space in each case study given its singular location by the edge of the water. Its design guidelines have changed over the last years. Initially ornamentation and welfare were the main drivers of open space design, later sustainability became more prevalent. Recently urban design guidelines have focused on a place's identity. Sustainability and identity, in this case, depend on the relationship between the urban realm and the natural habitat (including water, plants and fauna) that meet in waterfront greenways. It is possible to observe this process through the following examples.

\subsubsection{The Design of Waterfront Greenway in FCN (Vancouver)}

In FCN Vancouver the waterfront greenway consists exclusively of a pedestrian and a cycle path because of its narrow width. The shape of the greenway itself suits the urban fabric to the expense of the riverfront and any meaningful relation with the water element, which is reduced to a contemplative function. The guidelines for sustainability were lacking on this point, however planners were aware of the need for such criteria in the near future. The proof being the FCN Vancouver Official Development Plan of 1990 where a chapter titled 'Sustainability in Northeast False Creek' focused on applicability, energy, noise mitigation, local procurement and job opportunities. It was common knowledge from 2011 that Northeast False Creek would be developed immediately after FCN Vancouver. At that time the application of sustainable guidelines wasn't compulsory albeit awareness of them was wide spread. The Development Plan concerned mostly the land use, movement, parking, loading and views; identity was not even mentioned.

\subsubsection{The Design of Waterfront Greenway in SoWa (Portland)}

In SoWa Portland the greenway is much more extensive and its form is continuous and regular as it follows the riverbank. This is the result of a strong commitment to revitalize the Willamette River and its watershed. This has been achieved by creating the following themes: ensure a clean and healthy river for fish, wildlife and people; integrate the riparian habitat, building communities of native vegetation and appropriate species based on the soil, light, moisture conditions, context and adjacent uses of the site that offer visual variety; enhance the habitat for 
wildlife and provide ecological functions, security and connections to urban spaces; utilize riverbank stabilization strategies that enhance the river and riverbank ecosystems; embrace the river as Portland's 'front yard' creating a vibrant waterfront district; and promote partnership and education linked to the natural world. This vision appears sustainable because it restores the life of a place previously highly polluted.

As it happens, in FCN Vancouver there is a footpath albeit located in the middle portion of the greenway with the purpose of differentiating the two resulting parts. The area by river is densely populated with native species and presents the least human interaction, whilst the area by the development site relates more to the residents with ornamental plants surrounding outdoor uses like kiosks, cafes and play areas. The landscape is also used as a protection from the uneven terrain. The design allows for all types of users including cyclists, walkers, joggers and skate-boarders to use the place for both leisure and commuting. The design of dedicated paths makes it safe for people of all ages and abilities to use the space, minimizing conflicts. It is also esthetically pleasing to alternate landscaped and paved areas, permeable where possible. This has been achieved with a thirty-foot public corridor in which a twelve-foot cycle-path and a footpath are separated by a landscape buffer to ensure safety and amenity. Pedestrian and cycle connections to the greenway from the adjacent urban spaces are safe, convenient, direct and well lit at night. The greenway trails provide a continuous corridor for recreation and commuting, mirroring the traditional role of the river and creating the unique character of the site.

Along the waterfront greenway some elements of SoWa Portland's past are re-used in the new design to preserve the site's history in its transition from industrial to urban. In addition to this, other elements are used to keep the identity of the site such as the water taxi stop by Ross Island Bridge, used as a viewpoint over Ross Island and Portland's skyline and a resting place, as well as more viewpoints at the end of special corridors and public access paths to the riverbank.

\subsubsection{The Design of Waterfront Greenway in SEFC (Vancouver)}

The waterfront greenway of SEFC Vancouver is the widest in this study. It presents the most irregular form, integrated as it is within the urban fabric, creating a broad landscaped space between the buildings. The development keeps the existing shoreline's morphology aiming at health and safety objectives such as providing fish habitats, a natural character of the park, a public access to the riverbank, views over the ferry docks and other recreational amenities. To connect the natural and urban realm is used to establish other shoreline improvements to facilitate public access. A few permanent habitable structures are allowed within a hundred feet of the water edge. The presence of the water is a constant feature along the greenway and often within it.

Like the previous projects of this study, Southeast FCN Vancouver offers an example of a greenway integrated within the surrounding natural habitat. The greenway by the seaside is very close to the edge of the water where pedestrians and cyclists go across the many parks of SEFC Vancouver, both East and West side. Located in the inlet by the central part of the waterfront are several community services such as commercial (both permanent and temporary), residential, institutional and amenities. All have access to the parks and the waterfront, including the elderly and the mobility impaired. In this active urban waterfront walkers and cyclists can choose between a by-pass path on the north side of Front Street and a slower multi-use path by the water's edge.

This area is extended south to the beating heart of the community, an open public space of approximately 0.2 hectares by Manitoba Street, anchored by the Salt Building. The historical relationship between the Salt Building and False Creek represents the identity of the site. Identity is also achieved by other means such as preserving strong visual and physical connections between the waterfront and the residential area and designing the water edge with plants and urban features to evoke the former use of the place. The latter is achieved through the pattern of landscape and decking, which mimic the former boat's 'slip-ways' in the wharf areas as well as the design of the boardwalks and pedestrian bridges in the inlet canal area. 


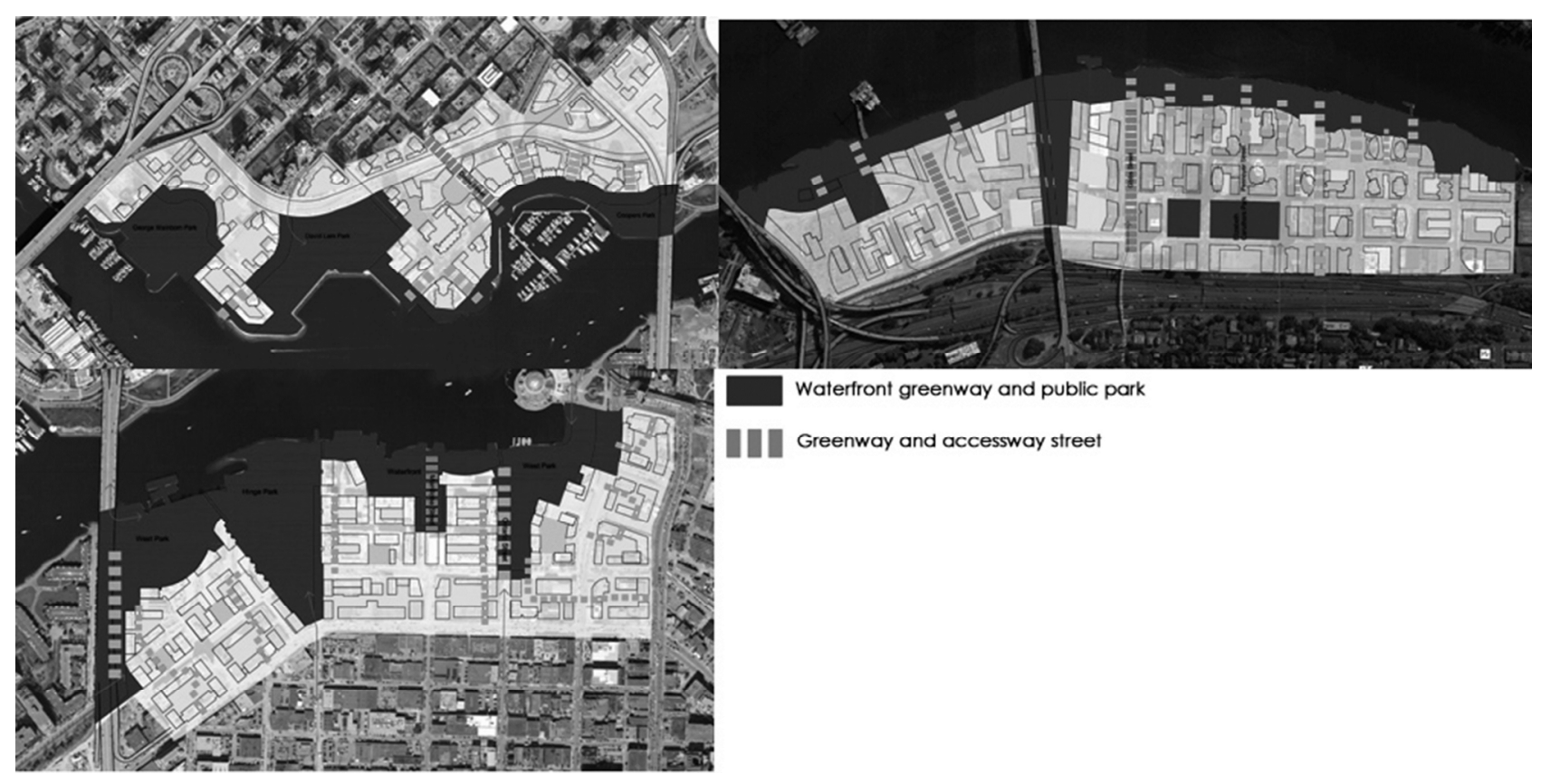

Figure 3. The different kinds of open spaces in each urban action project
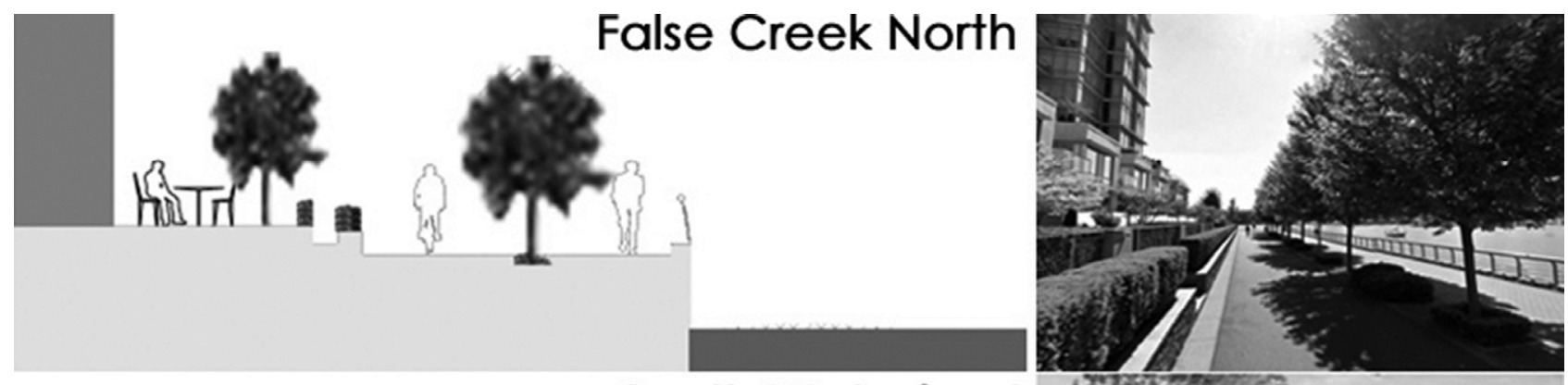

\section{South Waterfront}
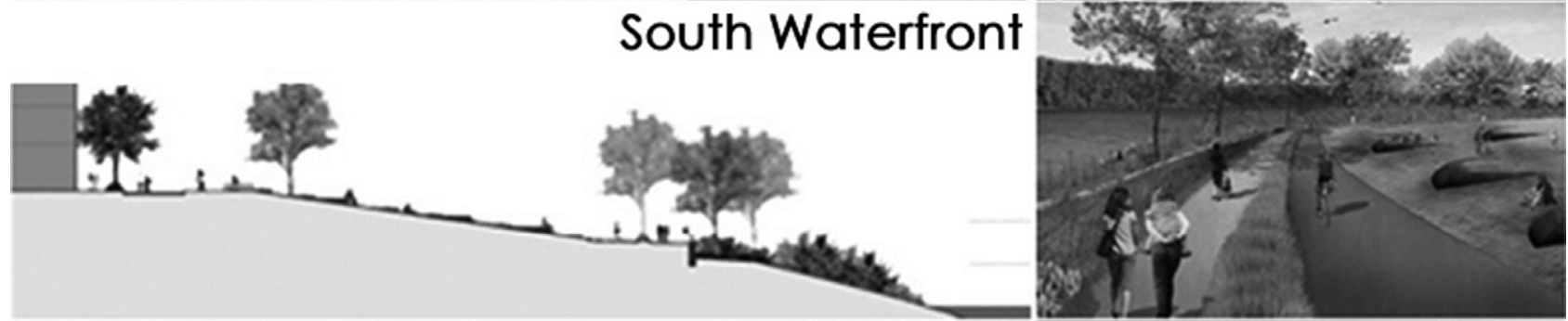

Southeast False Creek
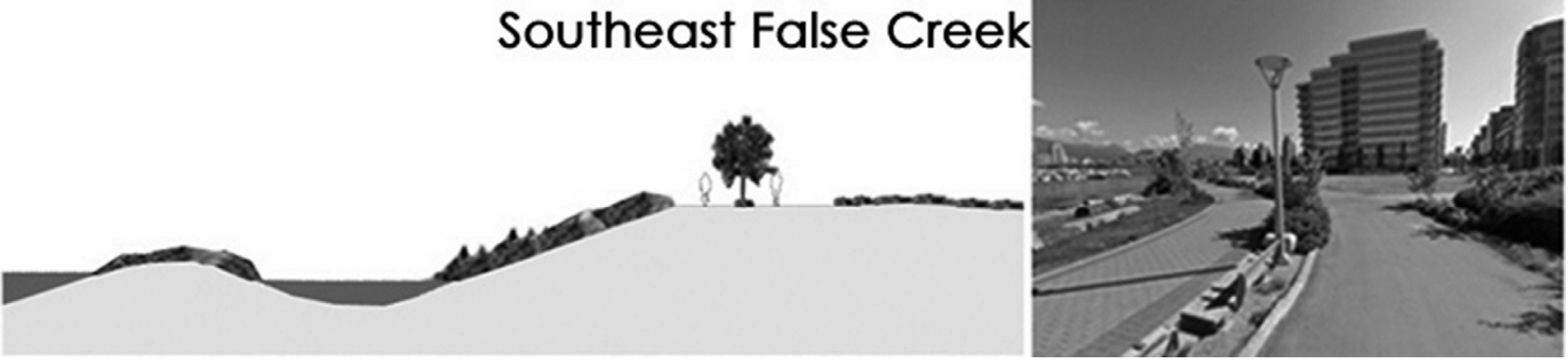

Figure 4. The design of the waterfront greenway in the different waterfront designs

4.4 Towards a Sustainable Identity through Public Parks

Two kinds of public parks were considered: parks and small pocket parks. Generally public parks are used to 
incentivize residential growth while small pocket parks serve the local community. Sustainability and identity are relevant to both dimensions.

\subsubsection{The Design of Public Parks in FCN (Vancouver)}

In FCN Vancouver there are three public parks: George Wainborn Park, David Lam Park and Coopers Park. Their geometric form responds to the urban fabric. Although they lay by the water's edge they only serve community uses such as resting and playing. Their design is artificial to the point that water becomes a mere ornamental element in fountains and pools. The only consideration for sustainability can be found in Coopers Park where the waterfront is extended under the Cambie Bridge to allow walking and cycling, reclaiming an area previously abandoned. Smoking is prohibited in these places to keep a safe and clean environment.

An example of small pocket park in FCN Vancouver may be the space between Landmark Tower (the second tallest tower in FCN) and Beatty Mews. Its North side overlooks Pacific Boulevard. Here the leaf motif design of a shallow pool on the floor surface is taken on a series of glass screens that decorate the sidewalk. Still "this is a space where form and function are not entirely successful" (Punter, 2003). It connects more to Beatty Mews than to the waterfront that is screened by trees and no direct path to it exists. Its design does not contribute to the sustainability or the identity of the place.

\subsubsection{The Design of Public Parks in SoWa (Portland)}

In SoWa Portland we studied two public parks: Elizabeth Caruthers Park and Ross Island Bridge Park. The dimension and form of Elizabeth Caruthers Park belong more to the urban fabric than to the riverfront greenway because of its location within the district. This Park is intended to serve as a gathering place for local residents providing a counterpoint to the highly urban district. It has a potential for handling storm-water in two ways: first by swales including trees, shrubs and grasses that filter and regulate the flow of rainwater, second by the use of porous pavement of different shapes and materials such as gravel, bricks and paving stones to allow ground infiltration. This exceptional design helps create a sense of place. The character of Ross Island Bridge Park is still difficult to work out but presents a more urban emphasis, including spaces for a farmers' market, water features, public art and walkways sheltered by the bridge. It produces a more natural light through the setting of the stream and showcases native plants along the innovative and attractive storm-water system. In addition to this Ross Island Bridge represents one of the district's most prominent historic landmarks providing a tall and visually interesting structure giving the park its unique identity.

The only small pocket park lay by a street junction. It is a natural rest stop for pedestrians and it is directly related to the greenway through a walkway. Sustainable guidelines are recognizable in the design of surfaces, plants compatible with the environment and furniture such as benches that retain rainwater.
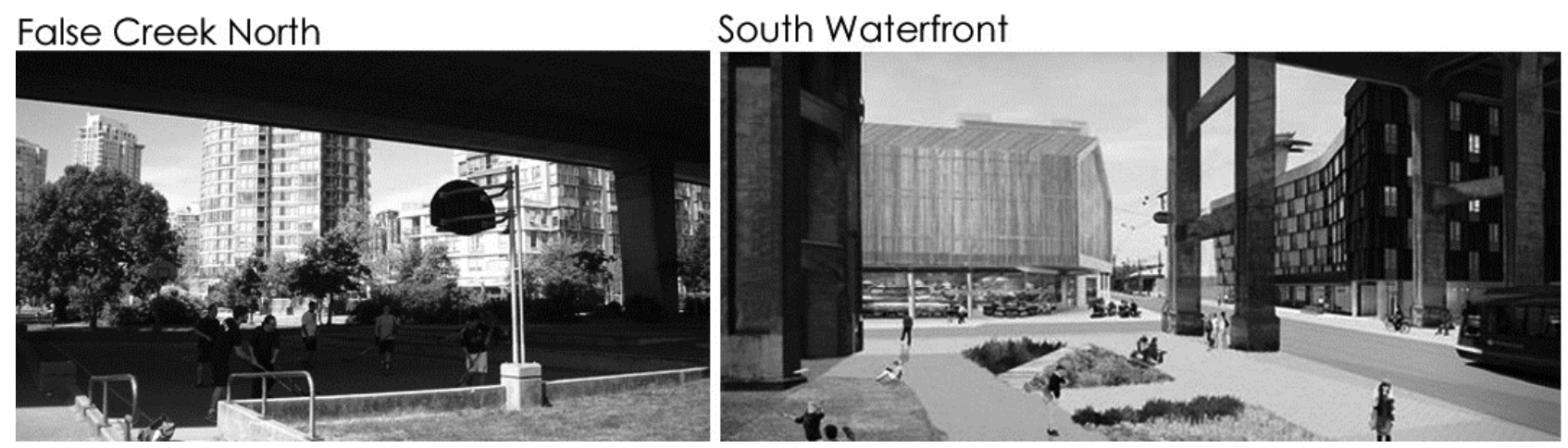

Figure 5. Coopers Park in FCN and Ross Island Bridge Park in SoWa

\subsubsection{The Design of Public Parks in SEFC (Vancouver)}

In SEFC Vancouver there are three public parks: Hinge Park, West Park and East Park. They are visually one single park as they seamlessly extend one after the other along the waterfront greenway. It is as if a spatial net holds them together whilst they break off the urban fabric. The development of these parks meets a number of objectives such as active and passive recreation, environmental sustainability and environmental learning. With regard to sustainability and environmental learning, these parks are part of the working infrastructure that deals with habitat restoration, storm-water retention and regulation, alternative energy applications and food production. The central Hinge Park is a public demonstration garden that shows how storm-water retention 
works by filtering and recycling. It lies between the community center and the school, which has garden plots and provides sustainability education for children and adults besides hosting a farmers' market. This park is designed as a visual demonstration of sustainability for the education of both visitors and residents.

Likewise the design of the small pocket parks in this area relates very much to the waterfront greenway contributing greatly to the identity, livability and character of each neighborhood. This is achieved through materials, artifacts, reuse of heritage structures, integration of public art and information. This space is a multi-layer interpretive experience that includes a variety of media structured on seven levels, each representing a layer in the interpretative strategy: image, interpretative node, replicated artifacts and sound station, original artifacts, linear interpretation, personal interpretation and interpretive panels. The themes and stories are assigned to various locations according to the site's history and heritage. An example of this is the Bridge Crane from the Canron Building proposed for the pocket park in the Worksyard Neighborhood which is left on site to represent its own identity. The same applies to the former Sawtooth Building in Worksyard, which was the former city machine shop, and to Wilkinson Steel Building, a former steel production shed located at the foot of Cook Street. These relics constitute the heritage of the area and provide tangible evidence of how the site was used over time and what it was like to work in a factory. The knowledge of their heritage stimulates people's emotional connection with the past, fostering a sense of place and encouraging stewardship.

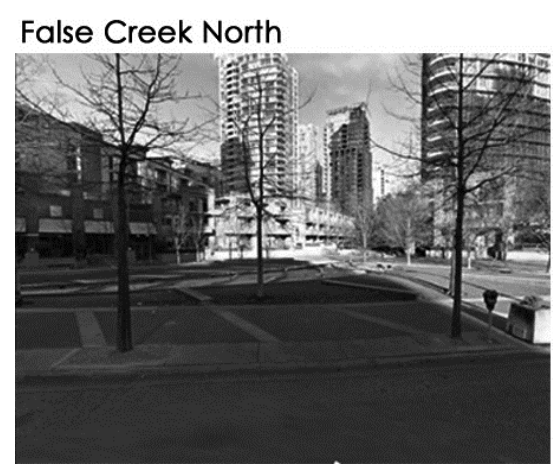

South Waterfront

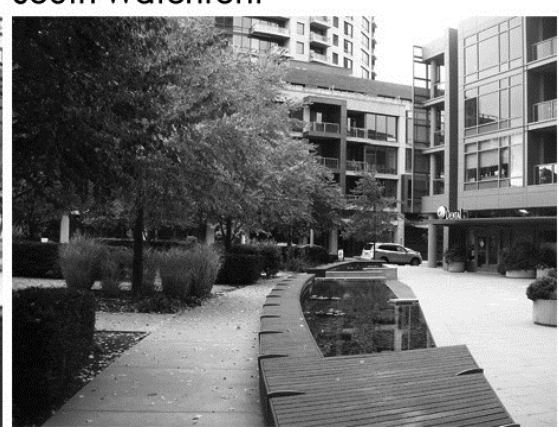

Southeast False Creek

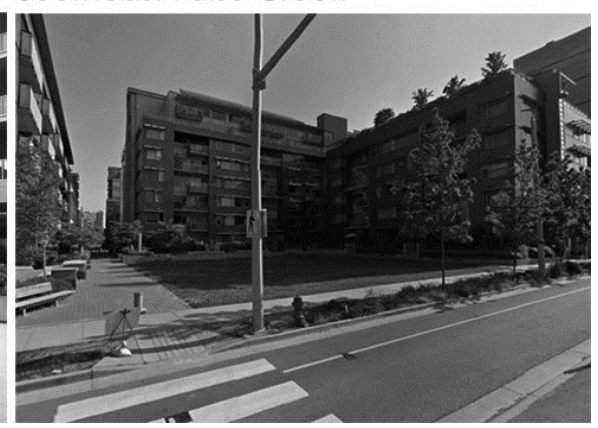

Figure 6. Small pocket parks in FCN, SoWa and SEFC

\subsection{Toward Sustainable Identity through Streets}

We considered two kinds of streets: access ways and greenways. The design of the access ways is guided by the need to connect the urban areas to the waterfront while the greenway's design requires protecting the natural environment and the habitat of the waterfront.

\subsubsection{The Design of Streets in FCN (Vancouver)}

In FCN Vancouver the main access way is Davie Street. Here private vehicles use up most of the street's width. There are also six greenways which are short in length; therefore they don't fully integrate into the old fabric.

\subsubsection{The Design of Streets in SoWa (Portland)}

In SoWa Portland there are four access ways: Bancroft Street, Gaines Street, Arthur Street and Gibbs Street. They connect the waterfront greenway to the western edge of the district and present a unique design. Gibbs Street is the most important because it presents the perfect entrance to the district with the potential for a 'transit hub'. Located here are the tram stop from Marquam Hill, River Parkway connection, I-5 overcrossing and access to Ross Island Bridge Park. At the same time, wider sidewalks provide a safe pedestrian experience and appropriate cycle-lanes to and from the greenway. The district obviously focuses on sustainable means of transport.

The design of the three greenways or 'fingers of green' -Lowell Street, Lane Street and Pennoyer Streetprovides for pedestrian and cycle access creating an exciting riverfront destination and connecting new and existing neighborhoods to and across the river, through trails, cycle-paths and view corridors. At the same time, they create an opportunity for multi-objective storm-water management systems like the bio swales where the water may be directed to the greenway for additional treatment. To achieve this it is necessary to encourage planting of native vegetation, which also offers a pleasing pedestrian and visual experience and enhances the habitat's wildlife. Impervious areas also minimize the urban development impact. The design of such greenways reinforces the setting of the river and its waterfront linking its landscape to the surrounding development. 
Access ways and greenways emphasize and integrate aspects of the diverse history of SoWa Portland using a variety of tools including paving materials, streetlights, street furniture and trees creating the unique character of the district's streets.

\subsubsection{The Design of Streets in SEFC (Vancouver)}

Manitoba Street is the main access way in SEFC Vancouver acting as the heart for the community. Pedestrians are the protagonist here, enjoying vast dedicated areas and solutions such as traffic signals at arterial intersections that facilitate safe crossing. An element of sustainability is the rainwater collection from the roofs of nearby buildings, which is directed into a tank beneath the plaza and overflows into False Creek. PV panels are placed along the length of the plaza to operate a water feature in the summer using the captured water. With regard to identity it is worth noting the preservation of the historic Salt Building and heritage elements re-used on site such as bollards and traditional weather protection features that enhance the historical qualities of the False Creek contributing to the identity of the place.

Greenways like the Ontario Street focus on storm-water management and urban agriculture. Rainwater from roofs, podiums and other surfaces is collected and stored on-site for high-efficiency drip irrigation systems, ultimately ending up in False Creek. Design guidelines specify the need for gardens in podiums and low and mid-rise concrete developments. These may be used for urban agriculture with on-site composting and rainwater collection.

In SEFC Vancouver the unique design of the entrance gateways creates a sense of expectation, enhancing the identity of the place. They are a recognizable element in the public realm creating the identity of the place and its component parts such as street trees, planting and paving.

\subsubsection{An Alternative Pedestrian Mobility in SoWa and SEFC}

Mid-block routes are unconventional paths that only exist in SoWa Portland and SEFC Vancouver. They create a sustainable identity for their residents through small details. These lanes connect courtyards creating a pedestrian friendly environment and landscape amenities despite the utilitarian nature of access and service of typical lanes. This is achieved through the design of outdoor restaurant seating, residential yards and well-landscaped areas to relax and play. They contribute to populate the courtyards connecting them through walkways ultimately leading to the waterfront, parks and commercial areas.

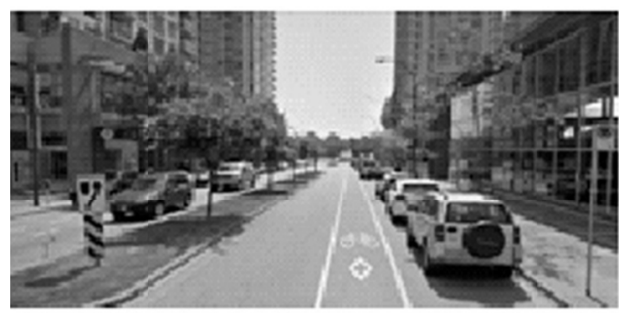

Davie Street (FCN)

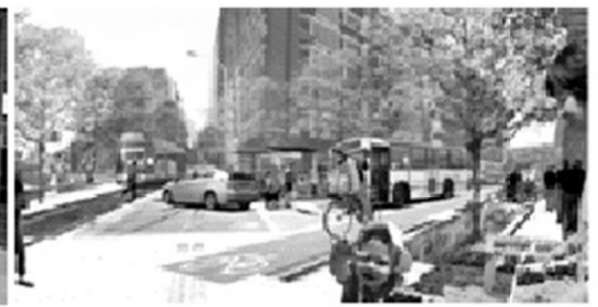

Gibbs Street (SoWa)

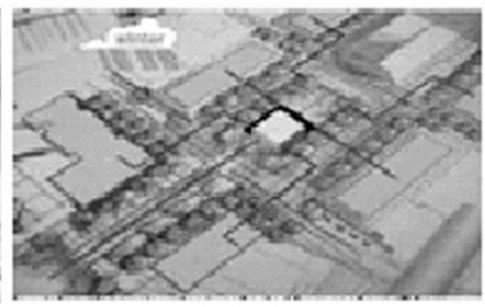

Manitoba Street (SEFC)

Figure 7. Streets in FCN, SoWa and SEFC

\section{Conclusion}

Sustainability and identity can be assessed in different ways according to the type of open space and the time of intervention. In the waterfront greenway design we have studied how the concept of sustainable identity varies from being completely absent in the case of FCN Vancouver to be the main design guideline in SoWa Portland and SEFC Vancouver. In the latter two cases the waterfront is recovered and returned to a natural environment with its wildlife habitat. Nevertheless the space also serves its urban function. Two fundamental elements appear to be necessary for the creation of a successful place: an active and populated waterfront and a greenway containing a trail. These two elements are treated in different ways in each of the project we studied. The trail loses prominence in FCN Vancouver where the waterfront greenway is just a continuous trail. In SoWa Portland the trail lay in the middle of the greenway producing a natural and urban strip. In SEFC Vancouver the trail loses its identity in a broad landscaped area. With regard to the active urban waterfront, it becomes a central element when merging with the riverbank enhancing the relationship with the water's edge. In FCN Vancouver the active urban waterfront of Marinaside Crescent has a character and design similar to that of a normal street of the city 
center. In SoWa Portland the active urban waterfront is in the middle of the greenway separated by a trail from the water's edge. In SEFC Vancouver the active urban waterfront is also found in the center of the greenway but in this case there is a strong relationship with the water's edge. Nature becomes the protagonist, colonizing the urban fabric, freeing space for the habitat at the expense of pedestrians and cyclists. The water's habitat and the identity of the place are increasingly contributing to the sustainability of places making them recognizable. The interplay between these two elements (urban fabric and waterfront) and the greenway habitat is the key to achieving a sustainable identity in the waterfront greenway.

With regard to public parks, sustainability and identity are to be found in the details. The storm-water management, the water treatment and the vegetation are the concerns of sustainability. With regard to small pocket parks, besides sustainability principles, they are used to generate a specific local character, with personality and identity. As we have seen in the case of FCN Vancouver, ornamental guidelines are very important, while in SoWa Portland the sustainability guidelines are of most concern and in SEFC Vancouver it is the need for identity.

In street design the most important elements are the pedestrian movement and the connection to the waterfront greenway. With regard to access-ways the balance of means of transport is the most important element to consider. We have seen in Manitoba Street how car access is losing out to pedestrian access as time passes. In greenway design, the sustainability guidelines appear like the main driver. Lanes within residential blocks provide a secondary pedestrian network, which enhances surveillance. Sustainability and identity are found in guidelines which affect transport means such as tram, bike and pedestrian as well as systems such as storm-water, vegetation planting and urban furniture design that retains the character of the site.

The relationship between sustainability and identity may be expressed by the scope of sustainability to preserve/restore the natural character of a place making it recognizable whilst identity focuses on the preservation of its personality by conserving its existing urban features. The main finding throughout this research is the ability of the identity to create not only sustainable urban design but also a sustainable society.

Therefore, the future direction of the urban design in waterfront areas is to create a sustainable identity through the art of making places for the people. It concerns the connections between people and places, movement and urban form, nature and the man-made environment and the process for achieving successful villages, towns and cities.

\section{Acknowledgement}

The authors would like to thank the University of Oregon for offering a 4-months (August-November 2013) Visitor Scholar opportunity to Prof. Nico Larco who was in charge of the Urbanism Department and Dr. Elena Lacilla who was a PhD student from the University of Navarra (Spain). Elena Lacilla was partially supported by Programa de Ayudas de Movilidad de la Asociación de Amigos de la Universidad de Navarra.

\section{References}

Alexander, D. H. M. (2001). From Brown to Green? Planning for sustainability in the redevelopment of Southeast False Creek. The Assessment and Planning Project BC Case Report 5.

Bezmez, D. (2009). The politics of urban waterfront regeneration: the case of Halic (the golden Horn), Istanbul. International Journal of Urban and Regional Research, 32(4), 815-840. http.//dx.doi.org/10.1111/j.1468-2427.2008.00825.x

Brown, L. R., Cuffney, T. F., Coles, J. F., Fitzpatrick, F., Mcmahon, G., Steuer, J., ... May, J. T. (2009). Urban streams across the USA: lessons learned from studies in 9 metropolitan areas. Journal of the North American Benthological Society, 28(4), 1051-1069. http.//dx.doi.org/10.1899/08-153.1

Butina Watson, G., \& Bentley, I.. (2007). Identity by design. Burlington, MA: Butterworth-Heinemann Elsevier.

De Sousa, C., \& D'souza, L.-A. (2012). South Waterfront district, Portland, OR: A sustainable brownfield revitalization. Best Practice. Institute for environmental science and policy. Sustainable brownfields consortium.

Designing urban agriculture opportunities for Southeast False Creek. 2007. City of Vancouver.

Eby, D. (2007). Still waiting at the altar: Vancouver 2010's on-again, off-again, relationship with social sustainability. COHRE Expert Workshop on Protecting and Promoting Housing Rights in the Context of Mega Events, Geneva, Switzerland.

False Creek North Official Development Plan. 1990. 
Goldsteen, J. B., \& Elliott, C. D. (1994). Designing America. Creating urban identity. New York, EEUU: Van Nostrand Reinhold.

Hagerman, C. (2007). Shaping neighborhoods and nature: Urban political ecologies of urban waterfront transformations in Portland. Oregon. Cities, 24(4), 285-297. http.//dx.doi.org/10.1016/j.cities.2006.12.003

Hardwick, W. G. (1994). Responding to the 1960s designing adaptable communities in Vancouver. Environment and behavior, 26(3), 338-362. http.//dx.doi.org/10.1177/001391659402600303

Hemphill, L., Mcgreak, S., \& Berry, J. (2004). As indicator-based approach to measuring sustainable urban regeneration performance: Part 2, empirical evaluation and case-study analysis. Urban Studies, 41(4), 757-772. http.//dx.doi.org/ 10.1080/0042098042000194089

Holden, M. (2012). Urban Policy engagement with social sustainability in Metro Vancouver. Urban Studies, 49(3), 527-542. http.//dx.doi.org/10.1177/0042098011403015

Holden, M., \& Scerri, A. (2013). More than this: Liveable Melbourne meets liveable Vancouver. Cities, 31, 444-453. http.//dx.doi.org/10.1016/j.cities.2012.07.013

Interpretative strategy Southeast False Creek. 2006. Stantec Architecture.

Kear, M. (2007). Spaces of transition spaces of tomorrow: making a sustainable future in Southeast False Creek, Vancouver. Cities, 24(4), 324-334. http.//dx.doi.org/10.1016/j.cities.2007.01.005

Mackie, J. (2006). What Vancouver needs 'is a tiny bit of grit'. The Vancouver Sun, September 9.

Malbert, B. (2010). Participatory approaches sustainable urban development: Reflections on practice Vancouver and Waitakere to in Seattle. Planning practice \& Research, 13(2), 183-189. http.//dx.doi.org/10.1080/13549830802522418

Maliene, V., Malys, N., \& Wignall, L. (2012). Brownfield regeneration: waterfront site developments in Liverpool and Cologne. Journal of Environmental Engineering and Landscape Management, 20(1), 5. http.//dx.doi.org/10.3846/16486897.2012.659030

Mendes, W., Balmer, K., Kaetchler, T., \& Rhoads, A. (2008). Using land inventories to plan agriculture. Experiences from Portland and Vancouver. Journal of America Planning Association, 74(4). http.//dx.doi.org/10.1080/01944360802354923

Paterson, D., \& Connery, K. (1997). Reconfiguring the edge city: the use of ecological design parameters in defining the form of community. Landscape and urban planning, 36, 327-346. http.//dx.doi.org/10.1016/S0169-2046(96)00363-5

Portland-Milwaukie: urban design elements. South Waterfront Station Area Open House. 2011. BATTY, Sean, HASTINGS, Bob.

Punter, J. (2002). Urban design as Public Policy: Evaluating the design dimension of Vancouver's Planning System. International Planning Studies, 7(4), 265-282. http.//dx.doi.org/10.1080/1356347022000027710

Quastel, N., Moos, M., \& Lynch, N. (2012). Sustainability-as-density and the return of the social: the case of Vancouver, British Columbia. Urban Geography, 33(7), 1055-1084. http.//dx.doi.org/10.2747/0272-3638.33.7.1055

Quayle, M. (1995). Urban greenways and public ways: realizing public ideas in a fragmented world. Landscape and urban planning, 33, 461-475. http.//dx.doi.org/10.1016/0169-2046(94)02034-D

Sepe, M. (2013). Planning and place in the city. Mapping place identity. New York, EEUU: Routledge, Taylor and Francis Group.

South Waterfront design guidelines and the greenway design guidelines for South Waterfront. 2002. The bureau of planning.

South Waterfront District. Street, Criteria and Standards. 2009. City of Portland, Bureau of transportation.

South Waterfront greenway development plan design component - phase I. 2004.

South Waterfront Plan. 2003 City of Portland, Bureau of Planning.

Southeast False Creek and Olympic Village - List of respondents to advance to next stage of selection process for the restoration and re-use of the Salt Building. 2006. City of Vancouver.

Southeast False Creek design considerations. Draft considerations for the Private Lands. 
Southeast False Creek Official Development Plan. 2005. City of Vancouver.

Southeast False Creek transportation study summary.

Southeast False Creek. Public Realm Plan. 2006. City of Vancouver.

The historic character of the private lands at Southeast False Creek. 2006. City of Vancouver.

Vollmer, D. (2009). Urban waterfront rehabilitation: can it contribute to environmental improvements in the developing world? Environmental Research Letters, 4, 7. http.//dx.doi.org/10.1088/1748-9326/4/2/024003

Wheeler, S. M. (2000). Planning for Metropolitan Sustainability. Journal of Planning Education and Research, 20, 133. http.//dx.doi.org/10.1177/0739456X0002000201

Wheeler, S. M. (2010). The evolution of Urban Form in Portland and Toronto: Implications for sustainability planning. Local environment: The International Journal of Justice and Sustainability, 8(3), 317-336. http.//dx.doi.org/10.1016/j.landurbplan.2013.04.002

Zoning code for South Waterfront. 2003. Bureau of Planning.

\section{Note}

Note 1. World Commission on Environment and Development, Our common future, Oxford University Press, 1987, p.1.

\section{Copyrights}

Copyright for this article is retained by the author(s), with first publication rights granted to the journal.

This is an open-access article distributed under the terms and conditions of the Creative Commons Attribution license (http://creativecommons.org/licenses/by/3.0/). 